\title{
Antimicrobial Treatment with the Fixed-Dose Antibiotic Combination RHB-104 for Mycobacterium avium subspecies paratuberculosis in Crohn's Disease: Pharmacological and Clinical Implications
}

Edoardo Savarino, Lorenzo Bertani, Linda Ceccarelli, Giorgia Bodini, Fabiana Zingone, Andrea Buda, Sonia Facchin, Greta Lorenzon, Santino Marchi, Elisa Marabotto, Nicola de Bortoli, Vincenzo Savarino, Francesco Costa \& Corrado Blandizzi

To cite this article: Edoardo Savarino, Lorenzo Bertani, Linda Ceccarelli, Giorgia Bodini, Fabiana Zingone, Andrea Buda, Sonia Facchin, Greta Lorenzon, Santino Marchi, Elisa Marabotto, Nicola de Bortoli, Vincenzo Savarino, Francesco Costa \& Corrado Blandizzi (2018): Antimicrobial Treatment with the Fixed-Dose Antibiotic Combination RHB-104 for Mycobacterium avium subspecies paratuberculosis in Crohn's Disease: Pharmacological and Clinical Implications, Expert Opinion on Biological Therapy, DOI: 10.1080/14712598.2019.1561852

To link to this article: https://doi.org/10.1080/14712598.2019.1561852

Accepted author version posted online: 21

Dec 2018.

Submit your article to this journal $\pi$

Џ Article views: 1

View Crossmark data $־$ 
Publisher: Taylor \& Francis

Journal: Expert Opinion on Biological Therapy

DOI: $10.1080 / 14712598.2019 .1561852$

\section{Antimicrobial Treatment with the Fixed-Dose Antibiotic Combination RHB-104 for Mycobacterium avium subspecies paratuberculosis in Crohn's Disease: Pharmacological and Clinical Implications}

Edoardo Savarino ${ }^{1}$, Lorenzo Bertani ${ }^{2}$, Linda Ceccarelli $^{2}$, Giorgia Bodini ${ }^{3}$, Fabiana Zingone ${ }^{1}$, Andrea Buda ${ }^{1}$, Sonia Facchin ${ }^{1}$, Greta Lorenzon ${ }^{1}$, Santino Marchi ${ }^{2}$, Elisa Marabotto ${ }^{3}$, Nicola de Bortoli ${ }^{2}$, Vincenzo Savarino ${ }^{3}$, Francesco Costa $^{2}$, Corrado Blandizzi ${ }^{4}$

${ }^{1}$ Gastrointestinal Unit, Department of Surgery, Oncology and Gastroenterology, University of Padua, Padua, Italy

${ }^{2}$ Gastrointestinal Unit, Division of Gastroenterology, Department of Translational Research and New Technologies in Medicine and Surgery, University of Pisa, Pisa, Italy

${ }^{3}$ Gastrointestinal Unit, Department of Internal Medicine and Medical Specialties, University of Genoa, Genoa, Italy

${ }^{4}$ Unit of Pharmacology and Pharmacovigilance, Department of Clinical and Experimental Medicine, University of Pisa, Pisa, Italy

Keywords: Crohn's disease, inflammatory bowel disease, Mycobacterium avium paracellulare, RHB-104, fixed drug combination, clarithromycin, clofazimine, rifabutin

\section{Corresponding Author:}

Edoardo Savarino

Division of Gastroenterology

Department of Surgery, Oncology and Gastroenterology

University of Padua

Via Giustiniani 2 
35128 - Padova - Italy

Phone: +390498217749

Fax: +390103538956

E-mail: edoardo.savarino@unipd.it

\section{Abstract}

Introduction: Crohn's disease (CD) is an inflammatory bowel disease of unknown etiology. However, increasing evidence suggests Mycobacterium avium subspecies paratuberculosis (MAP) as a putative causative agent: 1) MAP is the etiological agent of Johne's disease, a granulomatous enteritis affecting ruminants, which shares clinical and pathological features with CD; 2) MAP has been detected in tissues and blood samples from CD patients; 3) case reports have documented a favorable therapeutic response to anti-MAP antibiotics.

Area covered: This review provides an appraisal of current information on MAP characteristics, diagnostic methodologies and emerging drug treatments. The authors focus on RHB-104, a novel oral formulation containing a fixed-dose combination of clarithromycin, clofazimine and rifabutin, endowed with synergistic inhibitory activity on MAP strains isolated from CD patients.

Expert opinion: Based on encouraging in vitro data, RHB-104 has entered recently the clinical phase of its development, and is being investigated in a randomized, placebocontrolled phase III trial aimed at evaluating its efficacy and safety in CD. Provided that the overall clinical development will support the suitability of RHB-104 for inducing disease remission in CD patients with documented MAP infection, this novel antibiotic combination will likely take a relevant position in the therapeutic armamentarium for CD management. 


\section{Introduction}

Crohn's disease (CD) is a chronic transmural inflammation that may involve any part of the alimentary tract, from mouth to anus, and can be associated with several extra-intestinal co-morbidities. The disease onset usually falls within the second and fourth decade of life, with a smaller second peak described from 50 to 60 years. ${ }^{1}$ There is no gender-specific distribution in adult CD. Its incidence and prevalence are higher in economically developed than emerging countries, as well as in urban rather than rural areas. ${ }^{2}$ Asia, where some countries are undergoing a rapid urbanization, is witnessing an increase in the annual incidence of $\mathrm{CD} .^{3}$

$\mathrm{CD}$ is a chronic relapsing inflammatory disease, which presents frequently with abdominal pain, diarrhea, fever, and is often complicated by clinical signs of bowel obstruction, intestinal fistulization or both. ${ }^{4}$ The most frequent sites affected by the disease include the ileum, colon and perianal region, with a large prominence for the terminal ileum. The distribution of inflammatory activity throughout the intestine is characteristically segmental, and has a trend towards a life-long recurrence, even after resective surgery. The etiology of CD is unknown and several factors, both genetic and environmental in nature, have been implicated in its pathogenesis. As CD occurs frequently after infectious gastroenteritis, ${ }^{5}$ and it is characterized by a peculiar enteric microbial flora in terms of dysbiosis $^{6}$ and an increased number of intramucosal bacteria ${ }^{7}$, the efforts for identifying specific causative infectious agents have been endless. In this context, it is of interest that Mycobacterium avium subspecies paratuberculosis (MAP) has been identified as the etiological agent of Johne's disease, a severe granulomatous chronic enteritis affecting ruminants, which shares a number of clinical and pathological features with $C D$, including intermittent diarrhea, body weight loss, primary disease site in the ileocecal area, mucosal ulcerations and intramural granulomas. 
In addition to pathological and clinical analogies, MAP elicits also a similar pattern of immune response to $\mathrm{CD}^{8}$ and has been detected in both tissues and blood samples of adult ${ }^{9}$ and pediatric CD patients, ${ }^{10}$ thus raising problems of differential diagnosis in endemic areas. ${ }^{11}$ On the other hand, several case reports have documented a clearly favorable therapeutic response of CD patients to anti-MAP antibiotics ${ }^{12}$ and, given the close similarities of CD with Johne's disease, MAP has been hypothesized as a potential etiological agent of CD. However, even though a significant clinical association between MAP and CD has been established, the actual causative role of this agent in CD remains undetermined. ${ }^{13,14}$

Acknowledging the argumentation that a specific infectious agent, such as MAP, could act as the sole or major cause of CD would have dramatic implications for the prevention and therapeutic management of this challenging disease. At present, the ECCO guidelines ${ }^{15}$ do not support the use of systemically acting antibiotics (such as cyprofloxacine and metronidazole), due to the high incidence of adverse effects and the lack of clear evidence in support of their effectiveness. Likewise, these guidelines do not support antimycobacterial treatments, since a recent meta-analysis ${ }^{16}$ demonstrated that the only two trials that affected positively the disease activity included the administration of steroids to induce remission. Thus current international guidelines, based on a low level of evidence (conditional recommendation), do not recommend the use of anti-mycobacterial drugs as a first line therapy in $\mathrm{CD}^{15,17}$. Indeed, two previous meta-analyses reported that anti-mycobacterial therapy alone was not effective for the induction or maintenance of remission ${ }^{18,19}$.

In the present article, we have reviewed current information on MAP characteristics and the appropriate diagnostic methodologies for its detection in humans. The available data on emerging antibiotic formulations and novel anti-MAP treatment regimens in CD patients with MAP infection have been discussed as well. 


\section{Overview of the market}

Current therapeutic approaches, based on treatments with biotechnological drugs, have remarkably increased our expectations of favorable outcomes in the management of patients with severe forms of $\mathrm{CD} .^{20,21}$ However, up to $30-40 \%$ of naïve $\mathrm{CD}$ patients display a primary refractoriness to both traditional and biologic therapies. ${ }^{22}$ To overcome this issue, it has been suggested that patients with primary resistance should be investigated for MAP and, in case of confirmation, be treated with antimicrobial drugs targeted against mycobacteria. Currently, there is only one medicinal product directed against MAP under clinical development, that is RHB-104 (RedHill Biopharma).

\section{Introduction to the product}

\subsection{MAP: microbiological features, animal and human isolation and potential transmission routes}

MAP is a bacterium belonging to the family of Mycobacteriaceae and is included in the Mycobacterium avium complex (MAC), together with $M$. avium and $M$. intracellulare. MAP is a Gram-positive obligate intracellular pathogen, acid-fast and dependent on mycobactin for its replication (a lipo-soluble compound that allows iron metabolism). ${ }^{23}$ MAP cannot replicate outside of host cells and has a particular tropism for the colonization of intestinal tissues. Following oral ingestion, it undergoes internalization into the small bowel wall, and is carried to mesenteric or regional lymph nodes by dendritic cells or macrophages. ${ }^{24}$ At the subclinical stage of infection, the bovine immune response begins with the activation of cell-mediated Th1 pathway, while, at later stages, the immune response switches from Th1 to an antibodymediated humoral Th2 pathway, which is not able to eliminate intracellular pathogens. ${ }^{25}$

MAP was first isolated and described as the etiological agent of a chronic inflammatory bowel disease in cattle by Heinrich Albert Johne, a German veterinarian, in $1895 .^{24}$ The infection is transmitted primarily by fecal-oral route and is followed by a long latency period. 
Indeed, the majority of animals become infected within their first month of life, but the onset of clinical symptoms occurs after 3-5 years of age. The Johne's disease is known to develop and progress over four consecutive stages: silent, subclinical, clinical, and advanced. The infected animals do not display symptoms during the subclinical stage, while the infection becomes evident in the clinical stage, with diarrhea and weight loss. The advanced disease stage is associated with decreased milk production and presence of granulomatous formations both in the regional lymph nodes and small bowel tissues, followed by wasting and death. ${ }^{24,25}$

Humans can be exposed to MAP through a variety of routes, including food ingestion and environment. The environmental spread is related to shedding of MAP into the feces of infected ruminants, especially cows, and is the most likely route of transmission in Western countries, due to the ingestion of contaminated water: MAP DNA was indeed detected in over $80 \%$ of domestic water samples in Ohio (USA). ${ }^{26}$ MAP can also contaminate human alimonies, mainly meat and dairy products ${ }^{27}$. Pasteurization can reduce significantly, but not abolish this risk, as shown also in a study by Wynne et al. ${ }^{28}$, where MAP could be cultured from $1.8 \%$ of samples of pasteurized milk from MAP-positive cows in UK. Indeed, the thick lipid bacterial cell wall of MAP allows it to survive pasteurization, and live MAP has been detected in retail milk and cheese products. ${ }^{17}$

The serious concern for MAP transmission from cattle to humans is that MAP-infected cows remain asymptomatic in the subclinical stage. Then, infected cows do not undergo early identification and removal, and may continue to be harvested for milk and meat. As a consequence, MAP can spread unnoticed through fecal matters to the rest of herd. In addition, once released into the environment, MAP can survive for 12 weeks, and up to one year in soil or water. ${ }^{29}$ 
MAP has been suspected to be involved in many autoimmune disorders in humans: ${ }^{30,31} \mathrm{CD}$ susceptibility has been related to genes CARD15, SLC11A1, ${ }^{31}$ but there is a lack of data regarding the risk of developing CD in case of MAP infection.

\subsection{Diagnostic assessment of MAP infection}

Standard methods for detection of MAP infection in cattle rely on fecal culture or ELISA assays for anti-MAP antibodies. The sensitivity of both methods is low in subclinically infected animals, making difficult the eradication by culling. ${ }^{29}$ ELISA testing for antibodies has been often negative when used only once; therefore, this technique has been suggested as a tool for longitudinal follow-up. ${ }^{32}$ MAP suppresses actively the IFN- $\gamma$ - dependent immune response, and therefore the IFN- $\gamma$ release assay has been proposed as one of the most promising diagnostic tests for the early diagnosis of MAP infection. However, it has been observed that this assay can document only a condition of exposure to MAP, and that, when used in farm cattle, it is not able to discriminate infected from exposed animals. ${ }^{33}$

In the setting of CD patients, MAP takes a cell-wall deficient spheroplast-like form, which complicates the requirements for culturing and does not allow the use of the gold standard Ziehl-Nilsen mycobacterial staining test. ${ }^{34}$ Moreover, in human tissues MAP is difficult or often impossible to identify microscopically. Its presence can be identified by culturing, and indeed histopathological findings and tissue cultures can display high degrees of concordance (up to $80 \%$ ). However, the in vitro growth of MAP is very slow, and therefore from three to several months are required for colonies to appear. As suitable alternatives, molecular techniques, such as polymerase chain reaction (PCR) or in situ hybridization, can be employed also. ${ }^{35}$

\subsection{Therapeutic management of MAP infection}


Clarithromycin (CLA), clofazimine (CLO), and rifabutin (RIF) have been used individually or in combination with other drugs to treat diseases associated with mycobacterial infections, including CD. ${ }^{13,36}$

CLA is one of the most prominent member of macrolides, a class of antibiotics widely employed for treatment of upper and lower respiratory tract infections. ${ }^{37}$ Macrolides share the same core molecular structure consisting of a macrocyclic lactone ring with various amino sugar side groups. Macrolides approved for clinical use are endowed with 14-, 15- or 16membered lactone ring. These antibiotics can be sub-classified into natural compounds (e.g., erythromycin) and semi-synthetic derivatives (e.g. CLA or roxithromycin). ${ }^{38}$ Macrolides exert bacteriostatic effects when employed at clinically relevant concentrations, and act by inhibition of protein biosynthesis through binding to the large $50 \mathrm{~S}$ ribosomal subunit. ${ }^{39}$ The condition of resistance to macrolides is very often associated with a mutation in the $23 \mathrm{~S}$ rRNA gene leading to a base change at either position 2058 or 2059 (E. coli numbering); these are critical rRNA residues involved in the binding of macrolides to bacterial ribosomes, including mycobacteria. ${ }^{40}$ Although $23 \mathrm{~S}$ rRNA gene mutations are believed to account for most of the acquired macrolide resistance, there is also evidence that other, yetuncharacterized, ribosome mutations may explain some acquired macrolide resistances in $M$. avium $^{41}$ Generally, all wild-type strains (antibiotic naïve) of $M$. avium are susceptible to macrolides. $^{42}$ When tested in vitro against M. avium, ${ }^{43}$ CLA was 8 - to 32 -fold more active than erythromycin, probably because the former can penetrate the lipid coat of mycobacteria more readily than erythromycin. ${ }^{44}$ In vitro, minimum inhibitory concentrations (MICs) ranging from 0.25 to $0.5 \mu \mathrm{g} / \mathrm{ml}$ have been estimated for CLA against MAP. ${ }^{45,46}$ Resistance of MAP to macrolides has been defined as CLA MICs of $64 \mu \mathrm{g} / \mathrm{ml}$ at $\mathrm{pH} 6.8$ and $32 \mu \mathrm{g} / \mathrm{ml}$ at $\mathrm{pH}$ 7.3-7.4. ${ }^{47}$ There is some evidence that CLA can induce clinical remission in CD patients, as compared with placebo in a randomized trial. ${ }^{48}$ However, in another randomized controlled 
study, CLA conferred some benefit to CD patients only in the first month of therapy, while it appeared to be ineffective for the following two months. ${ }^{49}$

A recent review ${ }^{37}$ evaluated the possible role of macrolides in the management of multidrug resistant M. tuberculosis, and concluded that CLA may serve as a complementary drug, increasing mycobacterial permeability to other antimicrobial agents and exerting its own immune-modulating effects. On these bases, macrolides should never be employed as the sole therapeutic agent for treatment of mycobacterial diseases. ${ }^{50}$

CLO is a R-imino-phenazine antibiotic, originally developed for treatment of tuberculosis. ${ }^{51}$ The key structural feature of R-imino-phenazines is the phenazine nucleus, bearing an alkylimino (R-imino) group at the $\mathrm{C}-2$ position and phenyl substituents at the $\mathrm{C}-3$ and N-10 positions of the phenazine nucleus. ${ }^{52}$ The basic nitrogen atom of the isopropylimino group at position C-2 of clofazimine contributes to its cationic amphiphilic properties. ${ }^{53}$

CLO has demonstrated impressive activity against various mycobacterial species. ${ }^{54,55}$ In addition, CLO can act synergistically with other antimicrobial agents, such as CLA, against several mycobacterial species, including M. avium. ${ }^{56}$ CLO exerts mainly bacteriostatic effects, while bactericidal actions against actively replicating bacilli are regarded as minor pharmacodynamic properties, with MIC values ranging from 0.06 to $2 \mu \mathrm{g} / \mathrm{ml}$ for $M$. tuberculosis. ${ }^{52,57}$ With regard for M. avium, a CLO MIC of $0.12 \mu \mathrm{g} / \mathrm{ml}$ has been estimated in vitro. ${ }^{58}$ The actual anti-mycobacterial activity of CLO remains unclear. For sure, its high lipophilicity enables an efficient transmembrane penetration and accumulation in fatty tissues, with a subsequent uptake by human mononuclear phagocytes, which are the same cells infected by mycobacteria. ${ }^{52}$ Moreover, CLO displays a redox potential of $20.18 \mathrm{~V}$ at $\mathrm{pH} 7.25$, thus favoring intracellular redox cycling. ${ }^{59,60}$ Above all, CLO has a peculiar property that is highly relevant to the management of mycobacterial diseases; indeed, despite its long half-life 
and extensive accumulation in tissues, it is associated with a poor risk of microbial resistance. ${ }^{61}$ that might depend on the availability of multiple targets. ${ }^{52,62}$

Despite its impressive antimicrobial activity against in vitro isolates of $M$. tuberculosis, CLO monotherapy was found to be unsuccessful in early studies on higher primates and humans. The combination of this inefficacy with serious adverse events, such as skin discoloration and psychiatric disturbances, including depression, was also a deterrent to clinical application. ${ }^{61}$ However, in 1981 CLO was recommended by the WHO for its inclusion as a component of multidrug treatment regimens for leprosy due to its useful combination of antimicrobial and anti-inflammatory properties. ${ }^{63}$ Moreover, CLO is being used as a replacement for rifampicin, with good outcomes in up to $67 \%$ of patients with lung disease caused by the M. avium complex. ${ }^{64}$ In a randomized, placebo-controlled trial, CLO was found to be ineffective in inducing CD remission. ${ }^{65}$ Interestingly, in a retrospective study, Van Ingen et al. ${ }^{66}$ observed that CLO concentrations were enhanced upon concomitant administration of a macrolide (azithromycin), and these findings have been taken as a basis to suggest the suitability of a combination of CLO with CLA for treatment of MAP.

RIF, previously designated as ansamycin or LM 427, is a spiropiperidyl-rifamycin that shares several properties of the rifamycin family members, such as rifampicin and rifapentine ${ }^{67}$ Rifampicin is commonly used for treatment of non-tuberculous mycobacterial infections. ${ }^{50}$ Like other rifamycins, it binds prokaryotic DNA-dependent RNA polymerases causing their inhibition. ${ }^{68}$ In Mycobacterium spp, RNA polymerase comprises five subunits, and the binding site of rifamycins lies within the $\beta$-subunit, which is the catalytic core of this enzyme. As a consequence, acquired resistance to rifamycin - that has been well documented in $M$. tubercolosis $-{ }^{69}$ is conferred primarily by mutations in the $r p o B$ gene, which encodes the $\beta$-subunit of RNA polymerase, ${ }^{70}$ even though a significant proportion of resistant M. avium strains may lack a missense mutation in this gene. ${ }^{71}$ Current evidence suggests that a similar 
clustering of resistance-associated mutations occurs also in other mycobacteria. ${ }^{48,72}$ In an interesting Dutch study, which evaluated the effects of various antimicrobial agents on nontubercular mycobacteria, CLA and RIF were the most active, with $87 \%$ and $83 \%$ of all isolates, respectively, that were found to be susceptible. ${ }^{73}$ In this setting, RIF displayed considerably lower MIC values than CLA for M. avium (MIC ratio 5-10), M. tuberculosis (MIC ratio 2-4) and M. leprae (MIC ratio 10). ${ }^{73-75} \mathrm{~A}$ recent study estimated a $\mathrm{MIC} \leq 0.25-16$ $\mu \mathrm{g} / \mathrm{ml}$ of RIF for M. avium in clinical isolates. ${ }^{76}$ Same results are observed for MAP in an interesting Italian study. ${ }^{77}$ Synergistic effects against $M$. avium, leading to an increase in the permeability of the outer cell envelope, have been observed with combinations of RIF and ethambutol. ${ }^{78}$ In addition, studies on patients with HIV and M. avium infection have reported that RIF could protect against the development of CLA resistance. ${ }^{79,80}$ For this reason, in lung diseases due to M. avium, RIF is always associated with CLA. ${ }^{50,81}$

Of interest, in 2009 Krishanan et a1. ${ }^{82}$ evaluated the susceptibility of MAP strains to different classes of drugs using MGIT (mycobacterial growth indicator tube) 960 system and the results were compared with those of radiometric (BACTEC) and agar dilution methods. The authors found that the MIC values determined by MGIT displayed a $80-100 \%$ agreement $(+1 \log 2$ dilution) and a $80 \%$ agreement $(+1 \log 2$ dilution $)$ with those estimated by BACTEC and agar dilution methods for CLO and RIF, respectively. For CLA, the MGIT method had greater agreement with the agar dilution method ( $70 \%$ at the same dilution) than the BACTEC method $(60 \%$ at $+1 \log 2$ dilution); the agreement rate increased to $100 \%$ at $+2 \log 2$ dilutions in all cases. Based on these findings, the authors concluded that the MGIT system can be used for rapid and reliable drug susceptibility testing of MAP. In another study, the same authors employed the MGIT method to evaluate the synergistic effects of 6-mercaptopurine against MAP when combined with other conventional antibacterial agents, including CLO, CLA and 
RIF. The results showed that 6-mercaptopurine might be synergistic with macrolides, and that the inhibitory activity of CLA against MAP seems to be enhanced by rifampicin. ${ }^{83}$

\subsection{Combination therapy: clinical studies}

The putative efficacy of antibiotic treatment regimens, based on combined administration of CLA, CLO and RIF, has been investigated in previous clinical experiences (Table 1). In 2007, Selby et al. ${ }^{13}$ reported the results of their phase III, parallel-group, placebo-controlled, double-blind trial, designed to assess the efficacy and safety of a combined therapy with CLA, CLO and RIF in patients with active CD. In this study, 213 patients under treatment with prednisolone (40 mg/day with a dose tapering in 16 weeks) were randomized to antibiotic therapy (CLA, CLO, RIF) or placebo for 2 years. CLA was started at the dose of $250 \mathrm{mg}$ daily for the first week, followed by $250 \mathrm{mg}$ twice daily for the second and third week, and then $750 \mathrm{mg}$ /day from week 4; the RIF dosage was escalated at the same time points using daily doses of 150, 300 and $450 \mathrm{mg}$; CLO was given at the dose of $50 \mathrm{mg}$ daily. The results showed a benefit of the antibiotic therapy over the first 16 weeks in combination with prednisolone; indeed, $66 \%$ of patients receiving antibiotic therapy were in remission at week 16, while in the placebo group the remission rate was $50 \%(\mathrm{P}=0.02)$. From week 16 to 52 , at least 1 relapse was observed in $39 \%$ of patients in the antibiotic arm and $56 \%$ of the placebo group $(\mathrm{P}=0.054)$. The differences among the two study groups decreased at week $104(26 \%$ and $43 \%$, respectively. $\mathrm{P}=0.14)$ and at 1 -year follow-up after treatment $(59 \%$ and $50 \%$, respectively, $\mathrm{P}=0.54)$. The study treatments were well tolerated, with discontinuations for adverse events only in 16 patients ( 8 in each arm). However, several adverse events were significantly more frequent in the antibiotic group, as compared with placebo: abnormal liver function $(2.3 \%$ vs $0.3 \%)$, vaginal candidiasis $(4.0 \%$ vs $0.8 \%)$, abdominal distension $(3.4 \%$ vs $0.8 \%)$, myalgia $(2.3 \%$ vs $0.3 \%)$, and urine discoloration $(2.8 \%$ vs $0.3 \%$, ). Moreover, from 
week 17 to 52 , arthralgia (3.5\% vs $1.2 \%)$ and tooth discoloration $(2.3 \%$ vs $0.2 \%)$ were the only adverse events significantly more common in the antibiotic than in the placebo group. The overall conclusion of this study was that the antibiotic treatment displayed a significant benefit in terms of remission induction after 16 weeks, even though in combination with a steroid, but there was no evidence for a prolonged benefit.

It is worthy to mention that, subsequently, Behr et al. ${ }^{84}$ performed a re-analysis of benefits in the early and late time points of the above trial. In particular, they performed an intention-to-treat analysis based on all patients recruited into the two study groups, and obtained a significant difference in favor of the antibiotic therapy not only at week 16 , but also at weeks 52 and $104(\mathrm{P}=0.003$ and $\mathrm{P}=0.005$, respectively). Some limitations of the trial carried out by Selby et al. must be acknowledged. First, no attempt was made to culture or perform polymerase chain reaction for MAP, and therefore no definite conclusions could be drawn about the effect of the antibiotic combination on the putative MAP infection. In particular, no assessment was allowed to record for the putative development of MAP resistance to the combined antibiotic treatment. Second, some concerns might pertain to the dosing and delivery of test drugs that might have been not adequate to obtain therapeutic efficacy (in particular, CLO was administered as a double encapsulated form, potentially hampering its appropriate delivery to the target sites). Third, the trial by Selby et al. was not designed to exclude the possibility of MAP reinfection during the course of therapy or in the follow-up period. Lastly, the study may have lacked sufficient statistical power to demonstrate a more substantial advantage for the subset of CD patients harboring the MAP infection, who were expected to benefit more likely from the combined antibiotic therapy. ${ }^{85}$

\section{Emerging therapeutic approaches: RHB-104, a multi-drug oral formulation}


RHB-104 (RedHill Biopharma) is a novel formulation that combines in a single pill the three active antibiotics tested in previous studies against mycobacteria. As mentioned above, their combination was used to avoid the development of antibiotic resistance (see Drug summary box). RHB-104 contains a fixed combination of $95 \mathrm{mg}$ CLA, $10 \mathrm{mg}$ CLO and 45 mg RIF. At variance with the regimen employed by Selby et al., this formulation allows taking the three antibiotics in a single pill and at lower antibiotic dosages.

\section{Clinical Efficacy}

\subsection{Pre-clinical studies: in vitro efficacy of RHB-104}

Alcedo et al. examined the in vitro activity of RHB-104 against mycobacterial strains isolated from CD patients ${ }^{46}$ In particular, these authors estimated the MIC of CLA, CLO and RIF individually, in two-drug combinations, and as present in the RHB-104 formulation, and they observed that the three-drug combination displayed the lowest effective concentration $(0.25-10 \mu \mathrm{g} / \mathrm{mL})$ as a result of the synergistic anti-bacterial activity exerted by the three antibiotics. The MIC for CLA-CLO-RIF in the RHB-104 formulation against 13 of 16 isolated MAP strains was $0.25 \mu \mathrm{g} / \mathrm{mL}(0.158 \mu \mathrm{g} / \mathrm{mL}$ CLA, $0.017 \mu \mathrm{g} / \mathrm{mL}$ CLO, and 0.075 $\mu \mathrm{g} / \mathrm{mL}$ RIF). When tested individually, at the above concentrations, CLA, CLO and RIF were not able to inhibit the MAP growth. The inhibition for the CLA-CLO and CLA-RIF regimens was $70 \%$ and $15 \%$, respectively. A complete inhibition of MAP growth for CLACLO and CLA-RIF regimens could be achieved only at higher levels than their concentrations in $0.5 \mu \mathrm{g} / \mathrm{mL}$ RHB-104. The CLO-RIF pair inhibited MAP growth by $90 \%$ when tested at their individual concentrations in $1.0 \mu \mathrm{g} / \mathrm{mL}$ RHB-104. Of note, the MICs of RHB-104 against non-MAP strains were higher, with the MIC against $M$. avium strains being $4.0 \mu \mathrm{g} / \mathrm{mL}$. Like for MAP strains, at these concentrations the individual drugs were unable to inhibit bacterial growth. Overall, current data support the view that combined low doses of 
CLA, CLO and RIF can exert a synergistic in vitro anti-MAP activity. The suitability of lower concentrations of a triple synergistic antibiotic combination could then allow the clinical use of more tolerable dose regimens, and this would translate into an improvement of the risk-tobenefit ratio of treatments for $\mathrm{CD}$, along with a decreased risk of the onset of bacterial resistance, particularly in the long-term setting.

In the study by Alcedo et al., ${ }^{46}$ the contents of RHB-104 capsule formulation could not be dissolved in a single compatible solvent. Therefore, each of the three antibiotics was dissolved in individual solvents, and the respective proportions of the active ingredients contained in the RHB-104 formulation were then recreated in vitro by applying appropriate concentrations of each antibiotic to bacterial cultures. Subsequently, the same authors succeeded in dissolving the contents of RHB-104 capsule formulation in a single solvent, and therefore they performed a further in vitro study where the RHB-104 formulation dissolved in a single solvent was compared with the combination of appropriate concentrations of CLA, CLO and RIF dissolved in individual solvents. The results showed that the MIC values estimated for the RHB-104 formulation against several MAP clinical strains were fairly similar to those yielded by the combined application of the three antibiotics dissolved in individual solvents $(\mathrm{MIC} \leq 0.2 \mu \mathrm{g} / \mathrm{ml}$ ), thus confirming the contention that the multi-drug RHB-104 formulation can exert a potent synergistic anti-microbial activity. ${ }^{86}$

\subsection{Clinical efficacy of RHB-104: phase III study}

Following the encouraging in vitro results obtained with RHB-104, ${ }^{86}$ this fixed-dose antibiotic combination is being tested in a multicenter, randomized, double-blind, placebocontrolled, parallel group phase III trial (clinicaltrials.gov NCT01951326) to evaluate its efficacy and safety in about 330 patients with moderately to severely active CD. Patients are randomized to receive five RHB-104 capsules administered orally BID, containing $95 \mathrm{mg}$ 
CLA, $45 \mathrm{mg}$ RIF, and $10 \mathrm{mg}$ CLO for 26 weeks. The primary outcome of the trial is clinical remission at week 26 , but there are various secondary outcomes, among which the reduction of Crohn's Disease Activity Index (CDAI) score by a minimum of 100 points and the remission rate from week 26 through week 52 are the most important ones. Of note, in this study various background treatments are allowed: mesalazine and related compounds; corticosteroids; azathioprine, 6-mercaptopurine or methotrexate; infliximab or adalimumab. This could result in a selection bias. However, according to the study design, all the concomitant medications must be at stable doses prior patient randomization, and all the included patients must have a CDAI score from 220 to 450, meaning that they must display a clinically active disease despite the intake of concomitant drugs. Among the various outcomes, changes in MAP blood status will be assessed by PCR, even though MAP positivity will not represent a main criterion for patient inclusion in the study. This might be regarded as a relevant limitation, but, on the other hand, an evaluation of MAP concentration changes - only in patients with ongoing infection - should provide evidence that RHB-104 is effective against MAP in vivo as well. Of note, a long-term population pharmacokinetic study is being implemented also as a part of the Phase III MAP US trial (clinicaltrials.gov NCT01951326). This trial has been estimated to be completed on April 2019.

As compared to the Selby study, ${ }^{13}$ the main strength of the ongoing trial on RHB-104 is the low dosage of the three antibiotics; indeed, due to their in vitro synergistic effect, the efficacy of RHB-1004 could be good and the adverse effects would probably be less, in terms of frequency and/or severity. Another important point is the detection of MAP: if this were an inclusion criterion, the data obtained with the ongoing trial would likely allow to understand whether the effect of RHB-104 depends actually on MAP suppression or result from other mechanisms. In this respect, if a good proportion of the included patients will carry a 
concomitant MAP infection, some information on the role of MAP in CD are expected to be obtained, as compared to the Selby study, where MAP was not detected at all.

An open label study, designed to assess the efficacy and safety of RHB-104 in about 100 patients with active $\mathrm{CD}(\mathrm{CDAI} \geq 150)$, after 26 weeks of participation in the MAP US study, is also ongoing, with an estimated completion on October 2019 (clinicaltrials.gov NCT03009396). In this trial, patients are treated with RHB-104 for 52 weeks with an openlabel regimen. This study is evaluating also the proportion of patients with MAP positive blood PCR at baseline and changes in MAP blood PCR associated with RHB-104 treatment. Like above, background treatments with anti-inflammatory/immune-modulating drugs are allowed. However, after 8 weeks of open-label therapy with RHB-104, these medications could be discontinued by the investigator, as clinically indicated. In addition, concomitant corticosteroids must undergo tapering after 4 weeks of treatment with RHB-104. In this openlabel trial, the primary outcome is the remission after 16 weeks of treatment with RHB-104, whereas the time to remission, the duration of remission, the duration of response and the time of response are secondary outcomes. Preliminary results have been released and the drug showed a good efficacy: $42 \%$ of patients achieved disease remission at week $16,{ }^{87}$ but extended data have not been published yet.

\section{Safety}

Both the ongoing phase III and open label studies have been designed to evaluate also the safety of RHB-104 in patients with moderate-to-severe active CD. Data are not yet available. However, no major concerns about safety are expected from these trials, mostly because the dosage of the three antibiotics is lower as compared to the Selby study.

\section{Conclusions}


The etiological agent accounting for the onset of CD remains largely unknown. However, there is some evidence to suggest that infectious microorganisms might act as stimuli for triggering and maintaining the condition of excessive immune activation that underlies the pathophysiology of $\mathrm{CD}$. In this context, much attention is being paid to MAP, basically for three main reasons: 1) this mycobacterium has been identified as responsible for the etiology of Johne's disease, a severe chronic enteritis of ruminants that shares with CD several clinical, pathological and immune activation features ${ }^{24}$ 2) MAP has been repeatedly detected in blood and gut tissues from CD patients; ${ }^{9,34} 3$ ) a number of case reports have documented a favorable impact of anti-MAP antibiotics on the clinical course of patients with $\mathrm{CD} .^{36,48}$ Based on this knowledge, it has been conceived that treatments with antibiotics targeting MAP might lend significant benefits in the therapeutic management of patients with $C D$. In vitro tests have identified CLA, CLO and RIF as antimicrobial agents endowed with good inhibitory activity on the growth of various mycobacterial species, including MAP. ${ }^{46}$ These observations encouraged the implementation of clinical trials to evaluate the efficacy of treatment regimens, based on combinations of CLA, CLO and RIF, in inducing the remission of active $\mathrm{CD}$, but the results of initial studies have not been fairly promising. ${ }^{13}$ More recently, a renowned interest is revolving around the possible combined clinical use of CLA, CLO and RIF for treatment of $\mathrm{CD}$, since in vitro tests on MAP strains isolated from $\mathrm{CD}$ patients showed that RHB-104, a novel oral 10 -mg formulation, containing $95 \mathrm{mg}$ CLA, $10 \mathrm{mg}$ CLO and $45 \mathrm{mg}$ RIF, was significantly more effective than each individual antibiotic and displayed a remarkable synergistic activity in suppressing mycobacterial growth. ${ }^{83}$ These interesting findings have prompted the design of novel clinical studies deputed to investigate the efficacy and safety of RHB-104 in patients with active CD. As a result, the first controlled clinical trial in this setting is currently ongoing, and it is expected to be concluded by middle 2019 . In conclusion, current knowledge, suggesting a possible involvement of MAP in the 
etiopathogenesis of $\mathrm{CD}$, taken together with the strong synergistic anti-MAP activity displayed in vitro by the fixed antibiotic combination contained in RHB-104, provides a solid rationale supporting the clinical program aimed at testing the efficacy of RHB-104 in CD patients.

\section{Expert opinion}

Owing to the lack of evidence on the etiological agents underlying $\mathrm{CD}$, all current options available for pharmacological interventions in CD patients, including traditional drugs and biologics, are devoted to counteract the inflammatory activity and downregulate the abnormal immune hyper-activation, through a variety of mechanisms, in an attempt of achieving clinical remission and, whenever possible, bowel tissue healing. ${ }^{17}$ Of note, as anticipated in the above sections, current guidelines do not recommend the use of systemically acting antibiotics in the management of $\mathrm{CD}^{15}$. However, if one acknowledges the theory that a specific infectious agent, such as MAP, could be the primary cause of $\mathrm{CD}$, this assumption might have a dramatic impact on the way physicians manage the disease, in terms of diagnostic procedures and, above all, therapeutic approaches. Indeed, the pharmacological suppression of the etiological agent would be expected to result in a definitive biological healing of the disease.

To recognize a specific etiological role for MAP in CD would translate into two main obvious consequences: a) importance of MAP detection in CD patients, as a part of the routine diagnostic work-up, commonly implemented for this disease in clinical practice; b) the need for identifying antibiotic-based treatment regimens, suitable to allow MAP eradication, with a consequent resolution of both clinical and pathological signs of disease activity. With regard to the latter point, the novel oral formulation RHB-104, containing a fixed combination of CLA, CLO and RIF, appears to be quite promising, due to the evidence 
from in vitro studies showing a synergistic inhibitory activity of this combination on MAP strains isolated from CD patients. ${ }^{46,86}$ Although the results of initial clinical studies on the possible remission of active CD by combined administration of CLA, CLO and RIF were not fairly encouraging, ${ }^{13}$ novel clinical trials to test the efficacy and safety of RHB-104 in CD patients are currently ongoing and, in case of positive outcomes, their results would likely have a significant impact on the therapeutic strategies for $\mathrm{CD}$. Indeed, the demonstration of efficacy for RHB-104 might dramatically change the therapeutic and clinical research scenarios in $\mathrm{CD}$, since MAP eradicating regimens by antibiotics might become either firstline therapeutic approaches or complementary interventions to be employed in combination with current anti-inflammatory/immune-modulating drug therapies. Likewise, should the reliability of RHB-104 for treatment of CD be demonstrated, it is likely that physicians would trust and prescribe such a new therapeutic option, perhaps giving initial priority to those patients with clear demonstration of MAP infection or primary resistance to current standard pharmacological treatments.

As discussed above, at present the clinical development program of RHB-104 is being focused on a phase III trial aimed at evaluating its ability of inducing clinical remission in patients with active CD, as compared to placebo. However, the experimental design of this trial does not take into account some relevant arguments that deserve careful consideration. In particular, given the uncertainties on the causative role of MAP in CD and considering that the abnormal immune activation in $\mathrm{CD}$ seems to depend also on individual genetic determinants, it cannot be ruled out that in some patient subgroups $\mathrm{CD}$ might be triggered either by non-infectious causative factors or by infectious agents other than MAP. On this basis, a trial design where RHB-104 is intended to be compared with placebo irrespectively of the MAP status of CD patients does not appear satisfactory. We propose instead that, prior to enrolment, CD patients should be investigated for the presence of MAP, and RHB-104 should 
then be tested comparatively in a double-blind way in CD patients with and without MAP infection. Indeed, a favorable outcome with RHB-104 would be expected mainly in the presence of MAP infection and, clearly, the achievement of favorable results in patients without MAP infection would lead to hypothesize the involvement of non-MAP infectious agents or alternative mechanisms of actions for RHB-104 unrelated to antimicrobial activities. An appropriate interpretation of clinical data generated by future trials could take also advantage by the isolation of MAP strains from CD patients at the time of diagnosis with the purpose of evaluating their in vitro susceptibility to RHB-104. In our opinion, this information could actually prompt physicians to include this antibiotic combination in their therapeutic armamentarium in $\mathrm{CD}$ patients, particularly in cases of primary resistance to standard regimens. In this respect, provided that a stringent program of clinical development is implemented over the near future, in order to link causally the efficacy of RHB-104 to the diagnostic evidence of MAP infection, it can be envisaged that in the next 5 years this novel antibiotic combination might likely be at the end of its registration path. 


\section{Funding}

This paper is not funded.

\section{Declaration of interest}

The authors have no relevant affiliations or financial involvement with any organization or entity with a financial interest in or financial conflict with the subject matter or materials discussed in the manuscript. This includes employment, consultancies, honoraria, stock ownership or options, expert testimony, grants or patents received or pending, or royalties.

\section{Reviewer Disclosures}

Peer reviewers on this manuscript have no relevant financial relationships or otherwise to disclose. 


\section{Drug Summary Box}

\begin{tabular}{|l|l|}
\hline Drug name & $\begin{array}{l}\text { RHB-104 (fixed-dose combination of } \\
\text { clarithromycin, clofazimine and rifabutin) }\end{array}$ \\
\hline Phase & III \\
\hline Indication & Crohn's disease \\
\hline Pharmacology description/mechanism of action & $\begin{array}{l}\text { Well documented in vitro synergistic inibitory } \\
\text { activity on clinical isolates of Mycobacterium } \\
\text { avium subspecies, paratubercolosis }\end{array}$ \\
\hline Route of administration & $\begin{array}{l}\text { Oral } \\
\text { Pivotal trial }\end{array}$ \\
\hline $\begin{array}{l}\text { MAP US Study: multicenter phase III trial to } \\
\text { evaluate the efficacy and safety of RHB-104 in } \\
\text { patients with moderate-severe active Crohn's } \\
\text { disease }\end{array}$ \\
\hline
\end{tabular}




\section{References}

Papers of special note have been highlighted as either of interest $(\bullet)$ or of considerable interest

$(\bullet)$ to readers.

1. Molodecky NA, Soon IS, Rabi DM, et al. Increasing incidence and prevalence of the inflammatory bowel diseases with time, based on systematic review. Gastroenterology 2012;142:46-54 e42; quiz e30.

2. Torres J, Mehandru S, Colombel JF, Peyrin-Biroulet L. Crohn's disease. Lancet 2017;389:1741-55.

3. Ng SC, Tang W, Ching JY, et al. Incidence and phenotype of inflammatory bowel disease based on results from the Asia-pacific Crohn's and colitis epidemiology study. Gastroenterology 2013;145:158-65 e2.

4. Baumgart DC, Sandborn WJ. Crohn's disease. Lancet 2012;380:1590-605.

5. Garcia Rodriguez LA, Ruigomez A, Panes J. Acute gastroenteritis is followed by an increased risk of inflammatory bowel disease. Gastroenterology 2006;130:1588-94.

6. Joossens M, Huys G, Cnockaert M, et al. Dysbiosis of the faecal microbiota in patients with Crohn's disease and their unaffected relatives. Gut 2011;60:631-7.

7. Darfeuille-Michaud A, Boudeau J, Bulois P, et al. High prevalence of adherent-invasive Escherichia coli associated with ileal mucosa in Crohn's disease. Gastroenterology 2004;127:412-21.

8. Lee JS, Shin SJ, Collins MT, et al. Mycobacterium avium subsp. paratuberculosis fibronectin attachment protein activates dendritic cells and induces a Th1 polarization. Infect Immun 2009;77:2979-88.

9. Di Sabatino A, Paccagnini D, Vidali F, et al. Detection of Mycobacterium avium subsp. paratuberculosis (MAP)-specific IS900 DNA and antibodies against MAP peptides and lysate in the blood of Crohn's disease patients. Inflamm Bowel Dis 2011;17:1254-5.

10. Lee A, Griffiths TA, Parab RS, et al. Association of Mycobacterium avium subspecies paratuberculosis with Crohn Disease in pediatric patients. J Pediatr Gastroenterol Nutr 2011;52:170-4.

11. Baumgart DC, Bernstein CN, Abbas Z, et al. IBD Around the world: comparing the epidemiology, diagnosis, and treatment: proceedings of the World Digestive Health Day 2010--Inflammatory Bowel Disease Task Force meeting. Inflamm Bowel Dis 2011;17:63944.

12. Oken HA, Saleeb PG, Redfield RR, Schimpff SC. Is Mycobacterium avium paratuberculosis the Trigger in the Crohn's Disease Spectrum? Open Forum Infect Dis 2017;4:ofx104.

13. **Selby W, Pavli P, Crotty B, et al. Two-year combination antibiotic therapy with clarithromycin, rifabutin, and clofazimine for Crohn's disease. Gastroenterology 2007;132:2313-9.

This article is important because it shows the first results of a therapy with CLA, CLO and RIF to treat $C D$ patients

14. Feller M, Huwiler K, Stephan R, et al. Mycobacterium avium subspecies paratuberculosis and Crohn's disease: a systematic review and meta-analysis. Lancet Infect Dis 2007;7:607-13. 15. Gomollón F, Dignass A, Annese V et al. 3rd European Evidence-based Consensus on the Diagnosis and Management of Crohn's Disease 2016: Part 1: Diagnosis and Medical Management. Journal of Crohn's and Colitis 2017;11:3-25.

16. Borgaonkar MR, MacIntosh DG, Fardy JM. A meta-analysis of antimycobacterial therapy for Crohn's disease. Am J Gastroenterol 2000;95:725-9 
17. Lichtenstein GR, Loftus EV, Isaacs KL et al. ACG Clinical Guideline: Management of Crohn's Disease in Adults. Am J Gastroenterol 2018;113:481-517

18. Borgaonkar MR, MacIntosh DG, Fardy JM. A meta-analysis of antimycobacterial therapy for Crohn's disease. Am J Gastroenterol $2000 ; 95: 725$ - 9 .

19.Feller M, Huwiler K, Schoepfer A et al. Long-term antibiotic treatment for Crohn's disease: systematic review and meta-analysis of placebocontrolled trials . Clin Infect Dis 2010 ; $50: 473-80$

20. Bodini G, Giannini EG, De Maria C, et al. Anti-TNF therapy is able to stabilize bowel damage progression in patients with Crohn's disease. A study performed using the Lemann Index. Dig Liver Dis 2017;49:175-80..

21.Savarino E, Bodini G, Dulbecco P, et al. Adalimumab is more effective than azathioprine and mesalamine at preventing postoperative recurrence of Crohn's disease: a randomized controlled trial. The American journal of gastroenterology 2013;108:1731-42.

22. Gisbert JP, Panes J. Loss of response and requirement of infliximab dose intensification in Crohn's disease: a review. The American journal of gastroenterology 2009;104:760-7.

23. Thorel MF, Krichevsky M, Levy-Frebault VV. Numerical taxonomy of mycobactindependent mycobacteria, emended description of Mycobacterium avium, and description of Mycobacterium avium subsp. avium subsp. nov., Mycobacterium avium subsp. paratuberculosis subsp. nov., and Mycobacterium avium subsp. silvaticum subsp. nov. Int J Syst Bacteriol 1990;40:254-60.

24. *Naser SA, Sagramsingh SR, Naser AS, Thanigachalam S. Mycobacterium avium subspecies paratuberculosis causes Crohn's disease in some inflammatory bowel disease patients. World J Gastroenterol 2014;20:7403-15.

This paper highlights how MAP could be a possible causative agent of $C D$

25. Salem M, Heydel C, El-Sayed A, Ahmed SA, Zschock M, Baljer G. Mycobacterium avium subspecies paratuberculosis: an insidious problem for the ruminant industry. Trop Anim Health Prod 2013;45:351-66.

26. Beumer A, King D, Donohue M. Detection of Mycobacterium avium subsp. paratuberculosis in Drinking Water and Biofilms by Quantitative PCR. App Environ Microbiol 2010;76:7367-7370

27. National Advisory Committee on Microbiological Criteria for Foods. Assessment of food as a source of exposure to Mycobacterium avium subspecies paratuberculosis (MAP). J. Food. Protect. 2010;73:1357-1397

28. Wynne JW, Bull TJ, Seemann T et al. Exploring the Zoonotic Potential of Mycobacterium avium Subspecies paratuberculosis through Comparative Genomics. PLoS One 2011;6(7):e22171

29. Koets AP, Eda S, Sreevatsan S. The within host dynamics of Mycobacterium avium ssp. paratuberculosis infection in cattle: where time and place matter. Vet Res 2015;46:61.

30. Sechi LA, Dow CT. Mycobacterium avium ss. paratuberculosis Zoonosis - The Hundred Year War - Beyond Crohn's Disease. Front Immunol. 2015 Mar 4;6:96. doi: 10.3389/fimmu.2015.00096. eCollection 2015. Review

31. Cossu D, Masala S, Sechi LA. A Sardinian map for multiple sclerosis. Future Microbiol. 2013 Feb;8(2):223-32. doi: 10.2217/fmb.12.135. Review.

32. Whitlock RH, Wells SJ, Sweeney RW, Van Tiem J. ELISA and fecal culture for paratuberculosis (Johne's disease): sensitivity and specificity of each method. Vet Microbiol 2000;77:387-98.

33. Weber MF, Verhoeff J, van Schaik G, van Maanen C. Evaluation of Ziehl-Neelsen stained faecal smear and ELISA as tools for surveillance of clinical paratuberculosis in cattle in the Netherlands. Prev Vet Med 2009;92:256-66. 
34. Jungersen G, Mikkelsen H, Grell SN. Use of the johnin PPD interferon-gamma assay in control of bovine paratuberculosis. Vet Immunol Immunopathol 2012;148:48-54.

35. Sechi LA, Scanu AM, Molicotti P, et al. Detection and Isolation of Mycobacterium avium subspecies paratuberculosis from intestinal mucosal biopsies of patients with and without Crohn's disease in Sardinia. The American journal of gastroenterology 2005;100:1529-36.

36. **Borody TJ, Leis S, Warren EF, Surace R. Treatment of severe Crohn's disease using antimycobacterial triple therapy--approaching a cure? Digestive and liver disease : official journal of the Italian Society of Gastroenterology and the Italian Association for the Study of the Liver 2002;34:29-38.

This work shows the rationale in order to treat $\mathrm{CD}$ with anti-mycobacterial therapy

37. van der Paardt AF, Wilffert B, Akkerman OW, et al. Evaluation of macrolides for possible use against multidrug-resistant Mycobacterium tuberculosis. The European respiratory journal 2015;46:444-55.

38. Retsema J, Fu W. Macrolides: structures and microbial targets. Int $\mathbf{J}$ Antimicrob Agents 2001;18 Suppl 1:S3-10.

39. Buriankova K, Doucet-Populaire F, Dorson O, et al. Molecular basis of intrinsic macrolide resistance in the Mycobacterium tuberculosis complex. Antimicrob Agents Chemother 2004;48:143-50.

40. Pfister P, Jenni S, Poehlsgaard J, et al. The structural basis of macrolide-ribosome binding assessed using mutagenesis of 23S rRNA positions 2058 and 2059. J Mol Biol 2004;342:1569-81.

41. Doucet-Populaire F, Truffot-Pernot C, Grosset J, Jarlier V. Acquired resistance in Mycobacterium avium complex strains isolated from AIDS patients and beige mice during treatment with clarithromycin. J Antimicrob Chemother 1995;36:129-36.

42. Nash KA, Inderlied CB. Genetic basis of macrolide resistance in Mycobacterium avium isolated from patients with disseminated disease. Antimicrob Agents Chemother 1995;39:2625-30.

43. Fernandes PB, Hardy DJ, McDaniel D, Hanson CW, Swanson RN. In vitro and in vivo activities of clarithromycin against Mycobacterium avium. Antimicrob Agents Chemother 1989;33:1531-4.

44. Rastogi N, Frehel C, Ryter A, Ohayon H, Lesourd M, David HL. Multiple drug resistance in Mycobacterium avium: is the wall architecture responsible for exclusion of antimicrobial agents? Antimicrob Agents Chemother 1981;20:666-77.

45. Rastogi N, Goh KS, Labrousse V. Activity of clarithromycin compared with those of other drugs against Mycobacterium paratuberculosis and further enhancement of its extracellular and intracellular activities by ethambutol. Antimicrob Agents Chemother 1992;36:2843-6.

46. ***Alcedo KP, Thanigachalam S, Naser SA. RHB-104 triple antibiotics combination in culture is bactericidal and should be effective for treatment of Crohn's disease associated with Mycobacterium paratuberculosis. Gut pathogens 2016;8:32. In this work are demonstrated the results of RHB-104 in vitro.

47. Brown-Elliott BA, Nash KA, Wallace RJ, Jr. Antimicrobial susceptibility testing, drug resistance mechanisms, and therapy of infections with nontuberculous mycobacteria. Clin Microbiol Rev 2012;25:545-82.

48. Graham DY, Al-Assi MT, Robinson M. Prolonged remission in Crohn's disease following therapy for mycobacterium paratuberculosis infection. Gastroenterology 1995;108:A826.

49. Leiper K, Martin K, Ellis A, Watson AJ, Morris AI, Rhodes JM. Clinical trial: randomized study of clarithromycin versus placebo in active Crohn's disease. Alimentary pharmacology \& therapeutics 2008;27:1233-9. 
50. Griffith DE, Aksamit T, Brown-Elliott BA, et al. An official ATS/IDSA statement: diagnosis, treatment, and prevention of nontuberculous mycobacterial diseases. American journal of respiratory and critical care medicine 2007;175:367-416.

51. Barry VC, Belton JG, Conalty ML, et al. A new series of phenazines (rimino-compounds) with high antituberculosis activity. Nature 1957;179:1013-5.

52. Cholo MC, Steel HC, Fourie PB, Germishuizen WA, Anderson R. Clofazimine: current status and future prospects. J Antimicrob Chemother 2012;67:290-8.

53. Funk RS, Krise JP. Cationic amphiphilic drugs cause a marked expansion of apparent lysosomal volume: implications for an intracellular distribution-based drug interaction. Mol Pharm 2012;9:1384-95.

54. Cariello PF, Kwak EJ, Abdel-Massih RC, Silveira FP. Safety and tolerability of clofazimine as salvage therapy for atypical mycobacterial infection in solid organ transplant recipients. Transpl Infect Dis 2015;17:111-8.

55. Cholo MC, Mothiba MT, Fourie B, Anderson R. Mechanisms of action and therapeutic efficacies of the lipophilic antimycobacterial agents clofazimine and bedaquiline. $\mathrm{J}$ Antimicrob Chemother 2017;72:338-53.

56. Ferro BE, Meletiadis J, Wattenberg M, et al. Clofazimine Prevents the Regrowth of Mycobacterium abscessus and Mycobacterium avium Type Strains Exposed to Amikacin and Clarithromycin. Antimicrob Agents Chemother 2016;60:1097-105.

57. Mothiba MT, Anderson R, Fourie B, Germishuizen WA, Cholo MC. Effects of clofazimine on planktonic and biofilm growth of Mycobacterium tuberculosis and Mycobacterium smegmatis. J Glob Antimicrob Resist 2015;3:13-8.

58. van Ingen J, Totten SE, Helstrom NK, Heifets LB, Boeree MJ, Daley CL. In vitro synergy between clofazimine and amikacin in treatment of nontuberculous mycobacterial disease. Antimicrob Agents Chemother 2012;56:6324-7.

59. Van Rensburg CE, Joone GK, O'Sullivan JF, Anderson R. Antimicrobial activities of clofazimine and B669 are mediated by lysophospholipids. Antimicrob Agents Chemother 1992;36:2729-35.

60. Yano T, Kassovska-Bratinova S, Teh JS, et al. Reduction of clofazimine by mycobacterial type 2 NADH:quinone oxidoreductase: a pathway for the generation of bactericidal levels of reactive oxygen species. J Biol Chem 2011;286:10276-87.

61. Reddy VM, O'Sullivan JF, Gangadharam PR. Antimycobacterial activities of riminophenazines. J Antimicrob Chemother 1999;43:615-23.

62. Feng $\mathrm{X}, \mathrm{Zhu} \mathrm{W}$, Schurig-Briccio LA, et al. Antiinfectives targeting enzymes and the proton motive force. Proc Natl Acad Sci U S A 2015;112:E7073-82.

63. Dey T, Brigden G, Cox H, Shubber Z, Cooke G, Ford N. Outcomes of clofazimine for the treatment of drug-resistant tuberculosis: a systematic review and meta-analysis. J Antimicrob Chemother 2013;68:284-93.

64. Field SK, Cowie RL. Treatment of Mycobacterium avium-intracellulare complex lung disease with a macrolide, ethambutol, and clofazimine. Chest 2003;124:1482-6.

65. Afdhal NH, Long A, Lennon J, Crowe J, O'Donoghue DP. Controlled trial of antimycobacterial therapy in Crohn's disease. Clofazimine versus placebo. Digestive diseases and sciences 1991;36:449-

66. van Ingen J, Egelund EF, Levin A, et al. The pharmacokinetics and pharmacodynamics of pulmonary Mycobacterium avium complex disease treatment. American journal of respiratory and critical care medicine 2012;186:559-65.

67. Crabol Y, Catherinot E, Veziris N, Jullien V, Lortholary O. Rifabutin: where do we stand in 2016? J Antimicrob Chemother 2016;71:1759-71.

68. Levin ME, Hatfull GF. Mycobacterium smegmatis RNA polymerase: DNA supercoiling, action of rifampicin and mechanism of rifampicin resistance. Mol Microbiol 1993;8:277-85. 
69. Zhang Y, Yew WW. Mechanisms of drug resistance in Mycobacterium tuberculosis. Int J Tuberc Lung Dis 2009;13:1320-30.

70. Telenti A, Imboden P, Marchesi F, et al. Detection of rifampicin-resistance mutations in Mycobacterium tuberculosis. Lancet 1993;341:647-50.

71. Kongpetchsatit O, Phatihattakorn W, Mahakunkijcharoen Y, Eampokalarp B, Boonyasopun J, Ramasoota P. Mutation in the rpoB gene of the rifampicin resistant M. avium complex strains from Thailand. Southeast Asian J Trop Med Public Health 2006;37 Suppl 3:165-73.

72. Klein JL, Brown TJ, French GL. Rifampin resistance in Mycobacterium kansasii is associated with rpoB mutations. Antimicrob Agents Chemother 2001;45:3056-8.

73. van Ingen J, van der Laan T, Dekhuijzen R, Boeree M, van Soolingen D. In vitro drug susceptibility of 2275 clinical non-tuberculous Mycobacterium isolates of 49 species in The Netherlands. Int J Antimicrob Agents 2010;35:169-73.

74. Heifets LB, Iseman MD, Lindholm-Levy PJ. Determination of MICs of conventional and experimental drugs in liquid medium by the radiometric method against Mycobacterium avium complex. Drugs Exp Clin Res 1987;13:529-38.

75. Dhople AM, Williams SL. The activity of rifabutin against Mycobacterium leprae in armadillos. Int J Antimicrob Agents 1997;9:169-73.

76. Schon T, Chryssanthou E. Minimum inhibitory concentration distributions for Mycobacterium avium complex-towards evidence-based susceptibility breakpoints. Int J Infect Dis 2017;55:122-4.

77. Zanetti S, Molicotti P, Cannas S, Ortu S, Ahmed N and Sechi LA. "In vitro" activities of antimycobacterial agents against Mycobacterium avium subsp. paratuberculosis linked to Crohn's disease and paratuberculosis. Ann Clin Microbiol Antimicrob. 2006 Nov 15;5:27.

78. Dhople AM, Ibanez MA. In-vitro activity of three new fluoroquinolones and synergy with ansamycins against Mycobacterium leprae. J Antimicrob Chemother 1993;32:445-51.

79. May T, Brel F, Beuscart C, et al. Comparison of combination therapy regimens for treatment of human immunodeficiency virus-infected patients with disseminated bacteremia due to Mycobacterium avium. ANRS Trial 033 Curavium Group. Agence Nationale de Recherche sur le Sida. Clinical infectious diseases : an official publication of the Infectious Diseases Society of America 1997;25:621-9.

80. Gordin FM, Sullam PM, Shafran SD, et al. A randomized, placebo-controlled study of rifabutin added to a regimen of clarithromycin and ethambutol for treatment of disseminated infection with Mycobacterium avium complex. Clinical infectious diseases : an official publication of the Infectious Diseases Society of America 1999;28:1080-5.

81. Griffith DE, Brown-Elliott BA, Langsjoen B, et al. Clinical and molecular analysis of macrolide resistance in Mycobacterium avium complex lung disease. American journal of respiratory and critical care medicine 2006;174:928-34.

82. Krishnan YK, Manning EJB, Collins MT. Comparison of three methods for susceptibility testing of Mycobacterium avium subsp. paratuberculosis to 11 antimicrobial drugs. J. Antimicrobial. Chemotherapy 2009; 4:310-316.

83. Krishnan MY, Manning EJB, Collins MT. Effects of interactions of antibacterial drugs with each other and with 6-mercaptopurine on in vitro growth of Mycobacterium avium subspecies paratuberculosis. J. Antimicrob. Chemother 2009; 64:1018-1023

84. Behr MA, Hanley J. Antimycobacterial therapy for Crohn's disease: a reanalysis. Lancet Infect Dis 2008;8:344.

85. Kuenstner JT. The Australian antibiotic trial in Crohn's disease: alternative conclusions from the same study. Gastroenterology. 2007;133:1742-1743 
86. Qasem A, Safavikhasraghi M, Naser SA. A single capsule formulation of RHB-104 demonstrates higher anti-microbial growth potency for effective treatment of Crohn's disease associated with Mycobacterium avium subspecies paratuberculosis. Gut Pathog 2016;8:45.

87. https://ir.redhillbio.com/news-releases/news-release-details/redhill-biopharma-elaboratesits-announced-positive-top-

line?fbclid=IwAR2k397OF4VusXkvYS5553GPfvURrmZzpqmAKoFp5IIRZbJtpkgBe9Ii1x $\mathrm{M}$ 
Table 1. Clinical studies on antimicrobial treatment for MAP

\begin{tabular}{|c|c|c|c|c|}
\hline Study & Study Design & Drugs used & $\begin{array}{l}\text { Study } \\
\text { Population }\end{array}$ & Results \\
\hline $\begin{array}{l}\text { Selby } 2007 \\
\text { Behr } 2008 \\
\text { (reanalysis) }\end{array}$ & $\begin{array}{l}\text { Phase III, parallel- } \\
\text { group, placebo- } \\
\text { controlled, } \\
\text { double-blind trial }\end{array}$ & $\begin{array}{l}\text { CLA was started at } \\
\text { the dose of } 250 \mathrm{mg} \\
\text { daily for the first } \\
\text { week, followed by } \\
250 \mathrm{mg} \text { twice daily } \\
\text { for the second and } \\
\text { third week, and } \\
\text { then } 750 \mathrm{mg} \text { /day } \\
\text { from week } 4 \text {; } \\
\text { RIF dosage was } \\
\text { escalated at the } \\
\text { same time points } \\
\text { using daily doses } \\
\text { of } 150,300 \text { and } \\
450 \mathrm{mg} \text {; } \\
\text { CLO was given at } \\
\text { the dose of } 50 \mathrm{mg} \\
\text { daily. }\end{array}$ & $\begin{array}{l}213 \text { patients } \\
\text { under } \\
\text { treatment with } \\
\text { prednisolone }\end{array}$ & $\begin{array}{l}66 \% \text { of patients } \\
\text { receiving } \\
\text { antibiotic therapy } \\
\text { were in remission } \\
\text { at week } 16 \text { vs } \\
50 \% \text { in the } \\
\text { placebo group. A } \\
\text { significant } \\
\text { difference in } \\
\text { favour of the } \\
\text { antibiotic group } \\
\text { was also observed } \\
\text { at weeks } 52 \text { and } \\
104\end{array}$ \\
\hline $\begin{array}{l}\text { clinicaltrials.gov } \\
\text { NCT01951326 }\end{array}$ & $\begin{array}{l}\text { Multicenter, } \\
\text { randomized, } \\
\text { double-blind, } \\
\text { placebo- } \\
\text { controlled, parallel } \\
\text { group phase III } \\
\text { trial }\end{array}$ & $\begin{array}{l}\text { Five RHB-104 } \\
\text { capsules } \\
\text { administered orally } \\
\text { BID ( } 95 \mathrm{mg} \\
\text { clarithromycin, } 45 \\
\text { mg rifabutin, and } \\
10 \text { mg clofazimine) }\end{array}$ & $\begin{array}{l}330 \text { patients } \\
\text { with } \\
\text { moderately to } \\
\text { severely active } \\
\text { CD }\end{array}$ & $\begin{array}{l}\text { Expected on April } \\
2019\end{array}$ \\
\hline $\begin{array}{c}\text { clinicaltrials.gov } \\
\text { NCT03009396 }\end{array}$ & $\begin{array}{l}\text { Open label study, } \\
\text { phase III }\end{array}$ & $\begin{array}{l}\text { RHB-104; a fixed- } \\
\text { dose combination } \\
\text { of } 95 \mathrm{mg} \\
\text { clarithromycin, } 45 \\
\text { mg rifabutin, and } \\
10 \text { mg clofazimine }\end{array}$ & $\begin{array}{l}100 \text { patients } \\
\text { with active } \\
\text { CD }\end{array}$ & $\begin{array}{l}\text { Expected on } \\
\text { October } 2019\end{array}$ \\
\hline
\end{tabular}

